\title{
Editorial
}

Interational Axchives of
Allergy
Immunology

Published online: June 14, 2014

DOI: 10.1159/000363447

\section{Psychological Stress and Asthma: A New Enemy Within}

\author{
Harissios Vliagoftis \\ Pulmonary Research Group and Department of Medicine, University of Alberta, Edmonton, Alta., Canada
}

At the end of the 19th century, the medical textbook of Sir William Osler [1] referred to asthma as 'a neurotic affection'. For a long time before this and decades afterwards, asthma was considered primarily as a psychogenic disease and psychological factors were considered to be important for symptoms to manifest. When it became evident that there is an inflammatory basis for asthma, the interest in the psychological issues related to the disease dissipated. As so often happens in science, our understanding then went full circle, and we soon realized that mind-body interactions do indeed affect many inflammatory processes directly, thereby contributing significantly to the pathogenesis of inflammatory disease. Mind-body interactions can affect health via a variety of physiological mechanisms, but these interactions are often difficult to define and even more difficult to study in reproducible disease models.

In humans, there is evidence for a direct link between mental state/health and asthma, but it is difficult to establish a causal relationship. Many of the relevant studies have been recently reviewed $[2,3]$. Human studies can generate strong data on associations between mental state or stress and asthma, but more direct evidence of causal interactions is difficult to obtain. Acute stress, for example, has been linked to both immediate and delayed exac- erbations of asthma in children [4], but inferences as to the mechanisms involved is not possible from these studies. Although it is almost 20 years since a National Heart, Lung and Blood Institute Workshop suggested that more work is needed in this area and put forth issues needing to be studied [5], we still have a poor understanding of these interactions. Identification of the exact mechanisms linking psychological stress to asthma development and/ or exacerbations requires better and more comprehensive animal models. One such model, building on previous knowledge regarding the interactions between stress and asthma appeared in a recent issue of International Archives of Allergy and Immunology [6].

The authors of this article used a mouse model of ovalbumin-induced allergic airway inflammation in association with restraint and forced-swim stress. They showed that repeated stress caused consistent increases in corticosterone levels throughout the 7 days of the trial. Ovalbumin challenge of these animals was found to cause an increase in corticosterone levels that was not affected by previous stress encounters. In the mice challenged with ovalbumin, stress increased the accumulation of total cells, eosinophils and lymphocytes in the airways, total PAS-positive cells in the airways and total eosinophils and levels of IL-13 in the lung, in compari-

\section{KARGER}

E-Mail karger@karger.com

www.karger.com/iaa
(C) 2014 S. Karger AG, Basel

$1018-2438 / 14 / 1642-0109 \$ 39.50 / 0$
Correspondence to: Dr. Harissios Vliagoftis

Department of Medicine, University of Alberta Edmonton, AB T6G 2S2 (Canada)

E-Mail harissios.vliagoftis@ ualberta.ca 
son to nonstressed mice. This difference between stressed and nonstressed mice was prevented when the mice were pretreated with RU-486, a glucocorticoid receptor (GR) antagonist; RU-486 had no effect on any of these markers in the nonstressed animals. Stress also increased airway hyperresponsiveness in the mice challenged with ovalbumin compared to the nonstressed mice, but RU486 showed only a trend towards reducing airway hyperresponsiveness. A glucocorticoid synthesis inhibitor had similar effects with RU-486. These effects were not the result of hyporesponsiveness or an altered responsiveness of stressed mice to glucocorticoids; dexamethasone was able to inhibit inflammation in all the groups of mice, whether they had been stressed beforehand or not. A previous study on stress and asthma showed that social disruption stress induces a decreased responsiveness of spleen cells to corticosteroids and at the same time decreased GR expression in the lungs [7]. The study by Okuyama et al. [6] used a more crude method of identifying responsiveness to glucocorticoids which may not have been as sensitive for detecting a minor decrease in responsiveness. The model used was similar to that of the study by Forsythe et al. [8]; the results differ, however, in that the current study suggests that endogenous glucocorticoids released as a result of stressful stimuli are responsible for the exacerbation of inflammation but may also play a role in the exacerbation of airway hyperresponsiveness. This result is contrary to the anti-inflammatory effects of glucocorticoids that are to be expected. The previous study showed that RU-486 had no effect on stress-induced exacerbation of inflammation [8].

The conclusion of the study by Okuyama et al. [6] regarding the proinflammatory effects of glucocorticoids may have been quite unexpected in the asthma field, but over the last few years, evidence is accumulating that glucocorticoids may mediate proinflammatory effects in other inflammatory models, especially models of CNS inflammation. Administration of LPS to animals that have received exogenous glucocorticoids leads to greater inflammatory injury of the liver and CNS compared to animals that have not received glucocorticoids [9]. Glucocorticoid-induced enhancement of acute CNS injury and inflammation depends on GR expression in myeloid cells, while the presence of GR on the endothelium may also participate by affecting endothelial permeability and facilitating the accumulation of inflammatory cells in peripheral tissues [10]. Follow-up studies would be required in order to identify the cell(s) responsible for the proinflammatory effects of stress-induced glucocorticoids in asthma and to understand the mechanism of these interactions.

Many studies have attempted to explain the proinflammatory effects of glucocorticoids in other systems. The glucocorticoid concentration is an important factor in determining whether the glucocorticoids will have suppressive or permissive effects on macrophages [11]. Glucocorticoids induce a rapid and sustained increase of NLRP3 inflammasome in macrophages [12], which leads to the increased production of inflammatory mediators in response to ATP. Glucocorticoids have a synergistic effect with TNF in the induction of proinflammatory genes from airway epithelia cells [13], and they can increase the proinflammatory effects of IL-6 [14]. The coactivation of GR and NF- $\mathrm{KB}$ leads to interactions with genes so that these transcription factors cannot interact individually [15]. In general, the coactivation of GR with various proinflammatory transcription factors can increase the targets of these factors and lead to proinflammatory effects (reviewed in [16]). These effects may allow glucocorticoids to enhance the immune response to danger signals and may be a mechanism for increasing immune protection during the fight-or-flight response. However, in certain chronic diseases, this synergistic effect may lead to detrimental outcomes. A number of pathways could therefore explain the glucocorticoid-induced exacerbation of inflammation observed in asthma in this latest study, and further study is needed to clarify these interactions.

It was also very interesting that the increase in airway inflammation in the stressed mice challenged with ovalbumin versus the nonstressed mice challenged with ovalbumin was evident only in the females [6]. A similar observation was made in a model of experimental autoimmune encephalomyelitis [17]. Female mice have higher baseline levels of corticosteroids in the blood and are less susceptible to experimental autoimmune encephalomyelitis; however, when chronically stressed, they exhibit a higher susceptibility which is dependent on GR signaling. The stressed female mice had a lower corticosterone response to disease onset than the nonstressed mice, but this was not the same in the males. This early decrease in corticosteroid response in the females may have accounted for their increased susceptibility to disease. A similar mechanism may be active in the case of stress and asthma, but this was not investigated in the study by Okuyama et al. [6]. The sex of the animals used may also explain, at least in part, the difference in the results between their study and that of Forsythe et al. [8]. 
This most recent study also underscores some limitations of mouse studies. Many published studies have been well-designed and executed, but each describes only a small part of the problem and the methods used are often so different that direct comparisons cannot be made. The models they use are usually limited to animals of a certain genetic background, age and sex; this means the results are not generalizable. Not using mice of both sexes or not including mice with various genetic backgrounds means we may overlook certain mechanisms and pathways that could improve our understanding of the diseases studied. Performing clinical studies without including varied populations and both sexes creates a similar problem, and if the sex is indeed so important, what else are we missing when we design our animal models? Recently, the microbiome was shown to be important for the development of certain immune responses [18]. With this in mind, to what extent does the microbiome affect the interactions between psychological stress and asthma? We could gen- erate similar questions about many other processes that affect lung inflammation, and then more studies are going to be needed.

The findings presented can generate new interest in the area of animal models for understanding the interactions between psychological stress and asthma. If endogenous glucocorticoids are linked to increased inflammation following stress, are they also mediating inflammation in other conditions? Are they the marker for some other change that occurs as a result of the stress, and if so, why do inhibitors prevent this effect? How can we solve these problems and advance our understanding of allergic diseases and the effects of psychological factors? A good start would be to have studies on models of asthma that are better-designed and more comprehensive, with many different parameters being observed and investigated simultaneously. Systematic comparisons of the different strains, routes of sensitization, sexes and environmental factors may supply the missing answers.

\section{References}

1 Osler W: The Principles and Practice of Medicine. New York, Appleton, 1892, pp 497-501.

-2 O'Byrne PM, Pedersen S, Schatz M, Thoren A, Ekholm E, Carlsson LG, Busse WW: The poorly explored impact of uncontrolled asthma. Chest 2013;143:511-523.

3 Van Lieshout RJ, Macqueen GM: Relations between asthma and psychological distress: an old idea revisited. Chem Immunol Allergy 2012;98:1-13.

4 Sandberg S, Jarvenpaa S, Penttinen A, Paton JY, McCann DC: Asthma exacerbations in children immediately following stressful life events: a Cox's hierarchical regression. Tho$\operatorname{rax} 2004 ; 59: 1046-1051$.

5 Busse WW, Kiecolt-Glaser JK, Coe C, Martin RJ, Weiss ST, Parker SR: NHLBI Workshop summary. Stress and asthma. Am J Respir Crit Care Med 1995;151:249-252.

-6 Okuyama K, Dobashi K, Miyasaka T, Yamazaki N, Kikuchi T, Sorai I, Takayanagi M, Kita $\mathrm{H}$, Ohno I: The involvement of glucocorticoids in psychological stress-induced exacerbations of experimental allergic asthma. Int Arch Allergy Immunol 2014;163:297-306.

-7 Bailey MT, Kierstein S, Sharma S, Spaits M, Kinsey SG, Tliba O, Amrani Y, Sheridan JF, Panettieri RA, Haczku A: Social stress enhances allergen-induced airway inflammation in mice and inhibits corticosteroid responsiveness of cytokine production. J Immunol 2009;182:7888-7896.
$>8$ Forsythe P, Ebeling C, Gordon JR, Befus AD, Vliagoftis $\mathrm{H}$ : Opposing effects of short- and long-term stress on airway inflammation. Am J Respir Crit Care Med 2004;169:220-226.

-9 Frank MG, Miguel ZD, Watkins LR, Maier SF: Prior exposure to glucocorticoids sensitizes the neuroinflammatory and peripheral inflammatory responses to $E$. coli lipopolysaccharide. Brain Behav Immun 2010;24:19-30.

10 Sorrells SF, Caso JR, Munhoz CD, Hu CK, Tran KV, Miguel ZD, Chien BY, Sapolsky RM: Glucocorticoid signaling in myeloid cells worsens acute CNS injury and inflammation. J Neurosci 2013;33:7877-7889.

-11 Lim HY, Muller N, Herold MJ, van den Brandt J, Reichardt HM: Glucocorticoids exert opposing effects on macrophage function dependent on their concentration. Immunology 2007;122:47-53.

12 Busillo JM, Azzam KM, Cidlowski JA: Glucocorticoids sensitize the innate immune system through regulation of the NLRP3 inflammasome. J Biol Chem 2011;286:38703-38713.

13 Lannan EA, Galliher-Beckley AJ, Scoltock $\mathrm{AB}$, Cidlowski JA: Proinflammatory actions of glucocorticoids: glucocorticoids and TNFa coregulate gene expression in vitro and in vivo. Endocrinology 2012;153:3701-3712.
14 Dittrich A, Khouri C, Sackett SD, Ehlting C, Bohmer O, Albrecht U, Bode JG, Trautwein C, Schaper F: Glucocorticoids increase interleukin-6-dependent gene induction by interfering with the expression of the suppressor of cytokine signaling 3 feedback inhibitor. Hepatology 2012;55:256-266.

15 Rao NA, McCalman MT, Moulos P, Francoijs KJ, Chatziioannou A, Kolisis FN, Alexis MN, Mitsiou DJ, Stunnenberg HG: Coactivation of GR and NFKB alters the repertoire of their binding sites and target genes. Genome Res 2011;21:1404-1416.

16 Busillo JM, Cidlowski JA: The five Rs of glucocorticoid action during inflammation: ready, reinforce, repress, resolve, and restore. Trends Endocrinol Metab 2013;24:109-119.

-17 Harpaz I, Abutbul S, Nemirovsky A, Gal R, Cohen H, Monsonego A: Chronic exposure to stress predisposes to higher autoimmune susceptibility in C57BL/6 mice: glucocorticoids as a double-edged sword. Eur J Immunol 2013;43:758-769.

18 Goto Y, Panea C, Nakato G, Cebula A, Lee C, Diez MG, Laufer TM, Ignatowicz L, Ivanov II: Segmented filamentous bacteria antigens presented by intestinal dendritic cells drive mucosal Th17 cell differentiation. Immunity 2014;40:594-607. 